\title{
Anterior cervical discectomy and fusion in young adults leads to favorable outcome in long-term follow-up
}

\section{Hirvonen, Tuomas}

2020-07

Hirvonen , T , Siironen , J , Marjamaa , J , Niemelä , M \& Koski-Palkén , A 2020 , ' Anterior cervical discectomy and fusion in young adults leads to favorable outcome in long-term follow-up ', The spine journal : official journal of the North American Spine Society , vol. 20 , no. 7 , pp. 1073-1084 . https://doi.org/10.1016/j.spinee.2020.03.016

http://hdl.handle.net/10138/328820

https://doi.org/10.1016/j.spinee.2020.03.016

cc_by_nc_nd

acceptedVersion

Downloaded from Helda, University of Helsinki institutional repository.

This is an electronic reprint of the original article.

This reprint may differ from the original in pagination and typographic detail.

Please cite the original version. 


\section{Journal Pre-proof}

Anterior cervical discectomy and fusion in young adults leads to favorable outcome in long-term follow-up

Tuomas Hirvonen, Jari Siironen, Johan Marjamaa, Mika Niemelä , Anniina Koski-Palkén

PII:

DOI:

Reference:

To appear in:

Received date:

Revised date:

Accepted date:
S1529-9430(20)30133-9

https://doi.org/10.1016/j.spinee.2020.03.016

SPINEE 58143

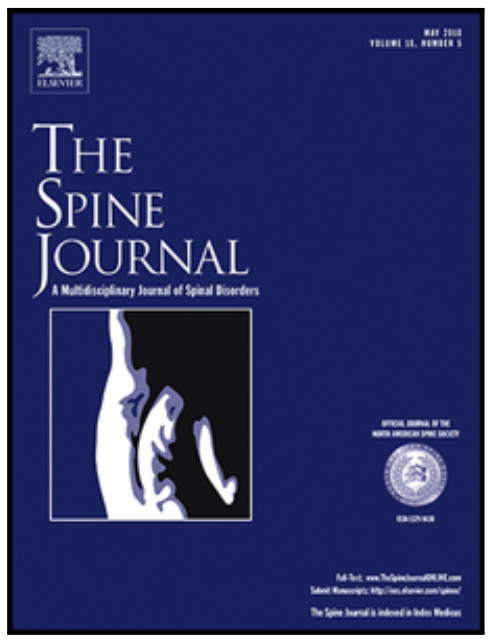

Please cite this article as: Tuomas Hirvonen, Jari Siironen, Johan Marjamaa, Mika Niemelä, Anniina Koski-Palkén, Anterior cervical discectomy and fusion in young adults leads to favorable outcome in long-term follow-up, The Spine Journal (2020), doi: https://doi.org/10.1016/j.spinee.2020.03.016

This is a PDF file of an article that has undergone enhancements after acceptance, such as the addition of a cover page and metadata, and formatting for readability, but it is not yet the definitive version of record. This version will undergo additional copyediting, typesetting and review before it is published in its final form, but we are providing this version to give early visibility of the article. Please note that, during the production process, errors may be discovered which could affect the content, and all legal disclaimers that apply to the journal pertain.

(C) 2020 Elsevier Inc. All rights reserved. 
Anterior cervical discectomy and fusion in young adults leads to favorable outcome in long-term follow-up.

Tuomas Hirvonen ${ }^{a}$, Jari Siironen ${ }^{a}$, Johan Marjamaa ${ }^{a}$, Mika Niemelä $^{\mathrm{a}}$, Anniina Koski-Palkén $^{\mathrm{a}}$

${ }^{a}$ Department of Neurosurgery, Helsinki University Hospital, Helsinki, Finland

Correspondence to:

Anniina Koski-Palkén, MD, PhD, Adj. prof.

Department of Neurosurgery

Helsinki University Hospital

Topeliuksenkatu 5, 00260 Helsinki

tel. +358504272054

anniina.koski-palken@hus.fi

None of the authors had financial affiliations. The only funding source of the study was research funding of Helsinki University Hospital. 


\section{Abstract}

Background Context Anterior cervical discectomy and fusion (ACDF) procedures is thought to lead to accelerated degeneration of the adjacent cervical discs and in some cases can be symptomatic (adjacent segment disease, or ASD). The occurrence of ASD is of particular interest when treating young individuals, as the cumulative disease burden may become increasingly significant during their expectedly long lifetime. However, the overall impact of a surgical intervention on the lifetime prognosis of ASD remains unclear.

Purpose Our goal was to study the long-term outcomes of ACDF surgery among those members of the young adult population who have been operated on between the ages of 18 and 40 .

Study design Retrospective study.

Patient Sample All patients between 18 and 40 years of age at the time of surgery who underwent ACDF due to degenerative cervical disorders at Helsinki University Hospital between the years of 1990 and 2005 (476 patients).

Outcome Measures Cervical reoperation rate, satisfaction with the surgery, employment status, Neck Disability Index (NDI)

Methods We retrospectively analyzed the medical records of all patients between 18 and 40 years of age at the time of surgery who underwent ACDF due to degenerative cervical disorders at Helsinki University Hospital between the years of 1990 and 2005. We sent questionnaires to all available patients at the end of the follow-up (median 17.5 years) to assess their current neck symptoms, general situations, and levels of satisfaction with the surgery. Furthermore, we compared the results for different types of ACDF surgeries (i.e., discectomy only versus synthetic cage or bone autograft implantation for fusion) in propensity-score-matched groups.

Results Of the 476 patients who were included in the study, surgery was performed in $72 \%$ of the cases due to intervertebral disc herniation and in $28 \%$ due to spondylotic changes. The total reoperation rate during the entire follow-up (median 17.5 years) was $24 \%$, and $19.5 \%$ if early reoperations (<28 days from index surgery) were excluded. At 10 years post-surgery, the total reoperation rate was $16.8 \%$ and $12.8 \%$ with early reoperations excluded. The probability of surgery for adjacent level disease was $10.3 \%$ at 10 years and $16.8 \%$ for the duration of the entire followup, with the annual incidence rate of $1.1 \%$ for those with ASD requiring surgery. Statistically significant risk factors leading to the need for further cervical surgery included central spinal cord compression and smoking at the time of the index operation. After propensity score matching, there was no significant difference found between the outcomes of different types of surgery. A total of 443 patients were still able to be contacted 12-28 years after the surgery. Of the 281 patients responding to the questionnaires, $92 \%$ were still satisfied with the results. With respect to employment, $67 \%$ of patients were working, $7 \%$ were unemployed, and $7 \%$ were on disability due to cervical problems. The median NDI score was $12 \%$, with $56 \%$ of patients having an NDI score lower than $15 \%$; it has been suggested that this latter NDI score serves as a cut-off value for significant neck morbidity. The NDI scores were significantly higher among female patients, patients with spondylosis, and patients having undergone further cervical surgeries during the follow-up. 
Conclusions Long-term satisfaction with the surgery was very high, and the employment rate among patients resembled that of the general population in Finland. Thus, the long-term prognosis after having ACDF surgery at a younger age seems to be good, even though nearly half of the patients experienced some persistent neck symptoms later in life.

Keywords: anterior decompression, cervical disc herniation, cervical spondylosis, reoperation, long-term outcome

\section{Introduction}

Anterior cervical discectomy and fusion (ACDF) is the leading surgical treatment of cervical radiculopathy caused by intervertebral disc herniation or spondylotic nerve root compression. Peak incidence rates of cervical radiculopathy are generally among those in the sixth decade of life, with spondylosis causing the majority of symptoms [1]. However, in the younger patient population, intervertebral disc herniations are more commonly the cause for radiculopathy. ACDF surgery leads to rapid pain relief and improved function, and the short-term results are very convincing [2] [3].What is not completely understood is the effect of surgery on long-term prognosis and whether it will lead to further procedures. It has been suggested that ACDF surgery might accelerate the degeneration of the adjacent cervical discs and, in some cases, lead to symptomatic adjacent segment disease (ASD). The total annual incidence of ASD has been reported in previous studies to be $2.9 \%$, and there is up to a $25.5 \%$ lifetime risk of developing postoperative ASD [4]. The need for reoperation due to ASD across unrestricted age groups has been evaluated in several studies [5] [6] [7] [8] [9] [10] [11] [12]. The estimates for the annual incidence rate of ASD requiring surgery vary from $0.8 \%$ to $2.4 \%$ [5] [6], with $7.2 \%$ of cases needing surgery in 25 years [8], and $22.2 \%$ in 10 years [6]. The occurrence of ASD is of particular interest when treating young individuals, as the cumulative disease burden from degenerative cervical disorders may become increasingly significant during their expectedly long lifetime. This can lead to a significant reduction in quality of life and higher overall health-related costs. Those patients treated in the Finnish health care system are assigned with personal identification numbers, making it possible to conduct reliable long-term follow-up studies. In the present study, we investigated the long-term results and reoperation needs for patients who were operated on with ACDF for intervertebral disc herniation or foraminal nerve root compression before the age of 40 years.

\section{Methods}

The study protocol and questionnaires were approved by the Helsinki University Hospital (HUH) ethics committee (HUS/2703/2017).

\section{Patient population}


We retrospectively collected the medical records of all patients between 18 and 40 years of age who underwent anterior cervical decompression surgery in the Department of Neurosurgery at HUH between the years of 1990 and 2005. The analysis was conducted between December of 2017 and February of 2018. The follow-up period ranged between 12 and 28 years. Only patients with degenerative cervical disorders (i.e., a herniated I.V. disc and/or spondylosis) were included in the study. Patients who were operated on because of a tumor, fracture, or other major trauma or epidural abscess were excluded. Also, patients with other cervical surgeries performed before this index surgery were excluded (including three patients who had undergone previous cervical laminectomies). A total of 476 patients were included in the study (Figure 1). Baseline information about the patient population is presented in Table 1.

\section{Surgical procedure}

All operations were performed under general anesthesia at the Department of Neurosurgery at HUH by fully-trained neurosurgeons (95\%) or senior residents (5\%). Indications for surgery in both primary operations and reoperations were either persistent symptoms after a minimum of six to eight weeks of conservative treatment with radicular pain, numbness or weakness in the upper extremities, or acute, severe symptoms with intolerable pain, and/or severe motor weakness with corresponding nerve root compression detected in an MRI. An anterior cervical discectomy (and osteophytectomy if needed) was performed on all patients. Sixty-four patients (13\%) underwent only a discectomy (during the years of 1990 to 1999). Interbody fusion with iliac crest autograft was performed on 84 (18\%) patients (between the years of 1990 and 1998). For the rest of the patients (328, or 69\%), fusion was performed with a synthetic interbody cage $\left(\right.$ BAK $^{\circledR}$, AcroMed $^{\circledR}$, Cervios $^{\circledR}$, CeSpace $^{\circledR}$ PEEK, CeSpace ${ }^{\circledR}$ Titanium, Rabea $^{\circledR}$, Ray $^{\circledR}$, SynCage $^{\circledR}$ ) (between the years of 1998 and 2005). Three (0.6\%) interbody fusions (one with a synthetic cage and two with iliac crest autograft) were reinforced with anterior plating. The median duration of hospital stays in the neurosurgical ward was three days (minimum of one day, and a maximum of 11 days). The majority of the patients were discharged after this period, and five patients were transferred from $\mathrm{HUH}$ to a regional hospital for further rehabilitation.

\section{Follow-up}

Patients were routinely invited for clinical follow-up visits. A total of 430 out of 476 patients (90\%) had clinical data available from their follow-up visits (median 67 days, min 15 days, max 340 days). 83\% of patients had their follow-up visits 2-3 months after surgery. There were some exceptions because of patient-related delays and issues, and 73 patients had more than one follow-up visit in the department. We evaluated the medical records from the follow-up visits and all further visits to HUH neurosurgery.

The clinical conditions of all patients at the post-operative visits were graded by using a five-point Likert scale (1=much worse than before the operation, $2=$ worse, $3=$ similar, $4=$ better, and $5=$ much better). The average duration of sick leave recommended from the Department of Neurosurgery at that time was 60 days. It is possible that patients got a further extension of sick leave from other health care units.

In the Finnish health care system, each patient has a unique identification number. Therefore, the same patients can easily be followed in medical records and contacted even after long intervals, leading to minimal loss of follow-up 
data. Due to the organization of the public health care system in Finland, surgery for degenerative cervical disorders is performed only by neurosurgeons, and surgeries are centralized to university hospitals. For instance, the HUH Department of Neurosurgery is responsible for performing all cervical surgeries for degenerative disorders in its catchment area (circa 1.6 million inhabitants at the time of the study period). Therefore, it is reasonable to assume that patients requiring reassessment or reoperation are generally referred back to the index department. The medical records of all 476 patients included in the study were thoroughly investigated, and data on all further re-referrals for surgical evaluation of cervical problems and all further cervical surgeries were collected.

In addition, we contacted all patients who were still living and residing at an available address in Finland (443 patients, or 93\%). Patients were sent a letter containing a customized survey of patient-reported satisfaction with surgery and their current general life situation, a Neck Disability Index (NDI) questionnaire, and a letter of informed consent. Of these patients, 281 (59\% of all patients in the study) returned the questionnaires. Furthermore, patients were asked to list any further cervical surgeries they may have had in order to confirm if there were any surgeries that for any reason would not have been indicated in the investigated medical records. It was noted that 24 patients had died during the follow-up period. Patient numbers for different parts of the study are represented as a flow chart in Figure 1. Information about complications, further cervical surgeries, and re-referrals was obtained from medical records for all patients included in the study.

\section{Statistical analysis and propensity score matching}

Statistical analysis was conducted using IBM SPSS Statistics 25 software. Statistical comparisons of the results (i.e., the Likert scale evaluations of conditions) between different patient groups (e.g., age, sex, or primary diagnosis) were made using the chi-squared test and student's t-test. P-values less than 0.05 were considered statistically significant. When using the student's t-test, the equality of variances was determined with Levene's test for equality of variances, and an appropriate t-test was then employed.

To further investigate differences in the groups of patients undergoing ACDF with either discectomy alone, an autograft bone implant, or a synthetic cage implant, propensity score matching (PSM) [13] was performed. A total of 64 patients had undergone surgery with a discectomy alone. Match cases from patients with implants (autograft or synthetic cage) were searched by using the PSM algorithm of SPSS software. Sex, primary diagnosis, number of levels operated on, and duration of the follow-up time were used as predictors (these variables were chosen because there was a statistically significant difference between discectomy and implant groups). The match tolerance level was set to the lowest possible value with which a match could still be found for every patient in the discectomy group ( 0.33 in the SPSS algorithm).

\section{Results}

\section{High number of clinical benefits at short-term follow-up visits}


The Likert scale evaluations of conditions at the post-operative follow-up visits are presented in Supplementary Table 1. While $91 \%$ of the patients reported their condition to be better or much better than before surgery, only $1 \%$ of patients reported a worse or much worse condition. A higher proportion of patients reported a benefit of Likert score 5 , i.e., a much better condition, among patients treated for disc herniation in contrast to patients with primarily spondylotic nerve root compression ( $56 \%$ vs. $46 \%, p=0.01$ ). However, considering the overall distribution of clinical scores, there was no significant difference between these groups (Supplementary Table 1).

In the subgroup analysis, the statistically significant independent factors affecting the clinical outcome at the time of the follow-up visit were implant type and the presence of central spinal canal stenosis with clinical signs of myelopathy (Figure 2). In addition, the presence of preoperative symptoms for over six months led to a significantly higher frequency of inferior clinical outcomes $(p=0.03)$ (Figure $2 B)$. The proportion of patients reporting better clinical conditions was higher if surgery had been performed using a synthetic cage rather than iliac bone graft or discectomy alone $(p=0.009)$. Notably, patients who had undergone iliac bone graft harvesting for fusion reported their conditions to be worse or much worse than prior to surgery in $6 \%$ of cases. Furthermore, patients with clinical myelopathy had significantly lower Likert scores than patients with no sign of central stenosis or only radiological findings $(p=0.033$ ). However, $87 \%$ of patients with clinical myelopathy were in a better clinical condition after the surgery. It was revealed that the presence of radiological central stenosis alone did not lead to inferior clinical results. However, patients with symptom durations of over six months were more likely to report significantly inferior clinical outcomes compared to patients with shorter symptom durations (Likert score of $1-3,12 \%$ vs. $5.5 \%, p=0.03$ ). Nevertheless, even patients experiencing over 12 months of preoperative symptoms generally benefited from the surgery $(86 \%$ with a Likert score of 4 or 5$)$.

As expected, surgery provided relief for all types of symptoms (including radicular or neck pain, and sensory or motor symptoms). The greatest effect was seen for radicular pain, with a reduction from $90 \%$ experiencing such pain preoperatively to only $10 \%$ of patients having some residual radicular pain postoperatively. The prevalence of neck pain also decreased from $54 \%$ to $32 \%$. Preoperative sensory or motor symptoms were reported at rates of $80 \%$ and $51 \%$, respectively, and these were reduced to $29 \%$ and $18 \%$ by the time of the clinical follow-up (Table 1 and Supplementary Table 1).

\section{Typical peri- and post-operative complications observed at tolerable levels}

Peri- and post-operative complications were analyzed from the medical records (Supplementary Table 2). The most common complications were post-operative hematomas (1,4\%), persistent dysphonia (4\%), or dysphagia (2\%) that were still bothersome at the time of the clinical follow-up visit, and new neurological symptoms (4\%) (typically sensory or motor nerve root symptoms) were also reported. All hematomas but one occurred acutely within 24 hours (with one occurring on the next day within 36 hours), and all were treated with a hematoma evacuation. Overall, $4.4 \%$ $(21 / 476)$ of patients required reoperation because of complications, with the reasons for such intervention including hematomas $(n=7)$, new neurological symptoms $(n=9)$, bone autograft problems $(n=3)$, and primary operation on the wrong level $(n=3)$. Three patients were reoperated on in acute settings two times (two because of new neurological 
symptoms, and one first because of residual disc herniation, and then a bone autograft problem). Overall, $30.8 \%$ of all complications led to a reoperation.

\section{Ten-year reoperation rate due to ASD: $10.3 \%$}

The median follow-up period was 17.5 years (min one year (one patient died one year after surgery), max 27.9 years). A total of $33 \%$ of the patients were referred back to the HUH neurosurgery department at least once for a new consultation regarding cervical spine problems (Table 2). Due to the organization of health care in Finland, patients requiring a reoperation or an assessment of their case are referred back to the index department servicing the geographical area. Thus, it is reasonable to assume that the available data contain information on nearly all of the reevaluations of our patients. Patients with no implant or an autograft were re-referred more often than patients with a synthetic cage $(p=0.004)$, which may also be due to the longer available follow-up times for this group of patients. Patients with spondylosis were re-referred more often than patients with disc herniation, but the difference was not statistically significant $(p=0.078)$. The annual risk of needing a new neurosurgical evaluation was therefore $2.7 \%$.

During the entire follow-up period of 17.5 years (median), 140 new cervical surgeries, either of the index level or of other cervical levels, were performed on 112 patients (24\%). All of these cervical reoperations were able to be categorized as either early revisions (<28 days from the primary operation) or late surgeries (>28 days). A total of $17 \%$ of reoperations $(n=24)$ were performed at an early period after surgery ( $<28$ days), and these consisted of the aforementioned revision surgeries to deal with post-operative complications. All early reoperations were either anterior decompressions of the same level (58\%), hematoma evacuations (29\%), or bone autograft removals (8\%). The risk of early revision surgeries was $4.4 \%$. We found that 13 later operations were done in hospitals other than HUH (11 in four other Finnish university hospitals, and two in a private hospital) (Table 2). Out of the later reoperations, $17 \%$ were performed during the first two years. Excluding early revision surgeries (<28 days) from the analysis, the reoperation rate during 10 years was $12.8 \%$ and $19.5 \%$ during the entire follow-up period, with a median of 6.9 years of time to reoperation (Figure $3 \mathrm{~A}$ ). The annual risk for a patient to require another cervical surgery later on during follow-up was $1.4 \%$ per year.

The most common reoperation type in both early and late reoperations was anterior decompression (70\% of all reoperations). Most late reoperations were performed on levels other than that of the index surgery (69\%). In fact, $84 \%$ of late ACDFs were performed on other levels, whereas all late laminectomies except for one (91\%) were on the level of the primary operation (all of them were multi-level laminectomies spanning other levels). Thus, laminectomy was often the method of choice when performing further surgery on the same level. Eight late foraminotomies were performed, and four were contained in the same level, while four were in other levels. Altogether, $23 \%$ of late reoperations involved further decompression of the index level, $82 \%$ involved decompression of the adjacent level, and 3\% involved decompression of the non-adjacent level. Therefore, 80 patients underwent surgery for ASD, and the risk of needing surgery for adjacent level disease was $10.3 \%$ in 10 years, and $16.8 \%$ for the duration of the entire follow-up (median 17.5 years), with a 1.1\% annual incidence rate of adjacent level disease requiring surgery.

\section{Clinical myelopathy and smoking as risk factors for cervical reoperations}


Risk factors of requiring at least one later reoperation ( $>28$ days) were central spinal cord compression ( $p=0,008$, with $16 \%$ of patients with no central compression, $30 \%$ of patients with only radiological stenosis, and $28 \%$ of patients with clinical stenosis being reoperated on at least once), implant type ( $p=0.011,17 \%$ synthetic cage, $21 \%$ bone autograft, and $33 \%$ discectomy only), and smoking at the time of the operation ( $p=0.001,31 \%$ smoking, and $14 \%$ non-smoking). Information about smoking was based on the questionnaires sent to the patients. Thus, only patients who responded were included in the analysis regarding smoking status. Men were reoperated on more often than women (22\% vs. $16 \%)$, but the difference was not statistically significant $(\mathrm{p}=0.074)$. Also, primary diagnosis $(21 \%$, spondylosis, and $19 \%$ disc herniation), age (<30 years at $16 \%$, and $>30$ years at $20 \%)$, number of levels operated on ( $20 \%$ one level, and $17 \%$ two or more levels), smoking at the present time (23\% smoking, and $20 \%$ non-smoking), and whether the primary operation was performed in an acute setting (23\% acute setting, and $19 \%$ non-acute setting) were not statistically significant factors.

Time to reoperation was analyzed with the Kaplan-Meier estimator, with early (<28days) revision surgeries excluded from the analysis (Figure 3). The statistically significant factors in the Kaplan-Meier survival estimates were spinal cord compression (median times: 6.8 years to reoperation with no central compression, 8.6 years only radiological, and 9.4 years clinical myelopathy, $p=0.007$, Figure 3 ), and smoking at the time of the operation (median times to reoperation: 9.0 years if smoking, and 8.6 years if not smoking, $p=0,001)$. Patients with disc herniation tended to undergo new cervical surgeries earlier, with a 6.8-year median time to new surgery versus a median of 11.0 years for patients with spondylotic nerve root compression $(p=0.057)$. However, the total percentage of patients undergoing new surgeries at least once was comparable $(21 \% \%$ and $19 \%$, respectively, $\mathrm{p}=0.544)$. Also, patients who had only had a discectomy (median times to reoperation: 7.0 years for synthetic cage, 10.4 years for bone autograft, and 4.9 years for only discectomy, $p=0,074$ ), and men (median times to reoperation: 7.4 years for men, and 5.9 years for women, $p=0.083$ ) were operated on more often, but these differences were not statistically significant based on the Kaplan-Meier analysis.

\section{Propensity matched cohort analysis dissolves differences in outcomes by fusion type}

Discectomy alone (without autograft or a synthetic cage for fusion) seemed to lead to a higher reoperation rate. In order to further investigate differences in groups of patients undergoing ACDF with either discectomy alone, an autograft bone, or a synthetic cage implant, we performed propensity score matching (PSM) to minimize confounding factors (Supplementary Table 3). Most differences between the groups disappeared with propensity matching, but there was still a significant difference in the duration of the follow-up (median 23 vs. 19 years, discectomy and others, respectively). After propensity matching, there was still a trend of more reoperations in the discectomy group, but the difference was not statistically significant ( $33 \%$ vs. $20 \%, p=0.109)$. The Kaplan-Meier analysis was also done with a propensity-score-matched cohort, and there were no statistically significant differences in time elapsed without new cervical surgery (data not shown).

\section{Patients report favorable subjective outcome assessment in the long-term}


Patients replied to a general information questionnaire for the study (Table 3). Again, a total of 281 of patients returned the questionnaires (59\% of all patients included in the study). Of these respondents, $67 \%$ of patients were working, and $13 \%$ were on disability, $56 \%$ of whom had cervical problems (or $7 \%$ of all patients that returned the questionnaires). It was revealed that $43 \%$ of the patients smoked at the time of the operation, and $25 \%$ were smoking at the time of the survey. Satisfaction with the surgery was evaluated on a Likert scale of $1-5$ (5=very satisfied, $1=$ very unsatisfied). It was shown that $92 \%$ were either satisfied or very satisfied with the surgery (score of $4-5)$, 3\% were either unsatisfied or very unsatisfied (score of 1-2), and $5 \%$ were indifferent. Patients were also asked if they would choose the surgery again in the same situation, and $96 \%$ reported that they would.

\section{NDI questionnaire and mild residual neck symptoms in long-term follow-up}

The patients completed an NDI questionnaire regarding the current state of their condition at the time of the study (Table 4), and 279 patients returned the NDI questionnaire. The NDI score is calculated and presented on a scale of 0$100 \%$, with higher numbers being correlated with worse functional ability [14] [15] [16]. The median score on the NDI among the patients was $12 \%$ (mean $18 \%$, $\min 0 \%, \max 84 \%$, standard deviation $17 \%$ ). Of the respondents, $56 \%$ of patients had an NDI score lower than $15 \%$, which has previously been estimated to be the cut-off value to detect neck pain associated with disability [17]. Women, patients with spondylosis, and patients with at least one further cervical surgery had significantly higher NDI scores compared to other groups. Also, patients with operations on two or three levels, or radiological signs/symptoms of central spinal canal stenosis had higher scores, but these differences were not statistically significant. The patients who were not satisfied with the results of the surgery had considerably higher scores compared to the satisfied patients. Implant type did not affect the NDI score.

\section{Discussion}

The aim of this study was to examine the long-term prognosis of young adult patients who have undergone anterior cervical procedures due to degenerative cervical disorders. To our knowledge, this is the first study to focus specifically on younger adult patients. These patients are of special interest since they are of working age with long careers ahead of them, and they could in general be very physically active. The strengths of our study include the large patient population and the minimal loss of patients during the follow-up period due to the organization of the Finnish health care system.

In general, satisfaction with surgery was high. At the post-operative follow-up visit several weeks after surgery, $91 \%$ of patients were in better clinical condition than before the surgery. At the time of questionnaire completion, 12-28 years after surgery, $92 \%$ of the patients were still satisfied with the results, and $96 \%$ reported that they would have chosen surgery again as the treatment option.

The most common surgical complications found in our study were persistent dysphagia (2\%) and dysphonia (4\%). The incidence rate of post-operative hematomas was $1.4 \%$. These numbers are within a range reported previously in another study (dysphagia: 2-67\%, dysphonia/recurrent laryngeal nerve palsy: $0.2-16.7 \%$, and hematoma: 1-10\%) 
[18]. The early reoperation rate (<28 days from the index surgery), or the revision surgery rate, was $4.4 \%$. In a recent study from the U.S. with over 50,000 patients, Kelly et al [19] found an early reoperation rate of $3.35 \%$ (<90 days). Thus, our results are in line with these findings (with only one reoperation being done between days 29-90 in our study). Lower early revision rates have also been reported, such as $2.07 \%$ in 90 days in the study conducted by Shousha et al [20]. As mentioned, the incidence rate of post-operative hematomas in our study was the same as previously reported levels [18]. Thus, the difference in early revision rates may reflect differences in clinical practices between neurosurgical units, countries, and eras. It is possible that the threshold for surgical revision on patients with some residual radicular or myelopathic symptoms after the primary surgery was lower in our unit in those years. One reason for this difference may also be related to the publicly-funded Finnish healthcare system, where patients or insurance companies are not responsible for the costs of revision surgery. Consequently, this may lead to earlier or even more active intervention in patients with residual symptoms after primary surgery. The mean post-operative hospital stay was three days based on the general practice of the era. At the present time, patients are typically discharged the next day after surgery.

Excluding early revision surgeries (<28 days), the reoperation rate during the rest of the follow-up period was $19.5 \%$, with a median of 6.9 years of time to reoperation. The 10 -year cervical reoperation rate was $12.8 \%$ excluding early reoperations. In a previous study conducted by our department, Saarinen et al reported the overall reoperation rate to be $15 \%$ in 10-12 years in a population of all ages, and $11 \%$ if the early reoperations (<1 month) were excluded [7]. The reoperation rate due to ASD was $10.3 \%$ in 10 years, and $16.8 \%$ for the entire follow-up period of a median 17 years, with a 1.1\% annual ASD surgery risk rate. Burkhardt et al [8] conducted a retrospective study similar in nature to ours in Germany, but with a patient population ranging from 26 to 61 years of age. They reported an overall reoperation rate of $17.2 \%$ over 25 years, with a reoperation rate due to degenerative cervical disorders of $10.7 \%$, and a reoperation rate due to ASD of $7.4 \%$. Despite a similar basic setting, there are major differences between our studies. In the study conducted by Burkhardt et al, all patients were operated on due to intervertebral disc herniation and with autograft bone with or without Caspar plating, and the sample represented all age groups. Also, it should be noted that higher reoperation rates have been published (Yue et al reported 16.9\% in 7.2 years [10], and Butterman et al reported $29 \%$ in 10.9 years [12]). However, most studies have focused on reoperations due to ASD, and estimates vary considerably (Chung et al reported a rate of $6.8 \%$ over 10-25 years [9], Ishihara et al reported a rate of 6\% over 10 years [11], Lee et al reported a rate of $22.2 \%$ over 10 years [6], and Butterman et al reported a rate of $21 \%$ over 10.9 years [12]). In contrast to the previous studies, our study only contained patients under the age of 40 . Conflicting results about age and the incidence rates of ASD have been reported: both young [5] and old [4] patients been found with different incidence rates of ASD, and some studies have reported no difference between age groups at all [11]. If the first operation is done while the patient is at a young age, there is more time for degenerative changes to develop, and thus more time for patients to end up needing a reoperation. Younger patients may also be more physically active, which may affect the development of ASD. Older patients have also experienced more degenerative changes at the time of the first surgery. On the other hand, higher reoperation rates have been reported in studies with older patients (Yue et al reported a rate of $16.9 \%$ in 7.2 years, with a mean age of 51 years [10]). Burkhardt et al [8] also suggest that the fact that all of their patients were operated on due to disc herniation could explain their low reoperation rates; furthermore, they have indicated that patient selection could have been more restricted at the 
time at which patients were operated on. In our study, there was no significant difference between the disc herniation and spondylosis groups, but there was a trend of patients with spondylosis needing new surgery later than patients with disc herniations.

In our series, smokers were reoperated on more often, and this result is in concordance with the work of Lee at al. [6]. Again, it was revealed that $43 \%$ of patients that returned the questionnaires smoked at the time of the operation, and $25 \%$ were still smoking at the time of the questionnaire. In comparison, $22-25 \%$ of Finnish adults smoked between 1996 and 2005, and 15\% in 2016 [21]. Therefore, it is apparent that smoking was significantly more common among patients in the past. As has also been previously reported, smoking is a risk factor associated with degenerative disc disease [22] [23], and as mentioned in previous studies as well as our own, smoking increased the risk of needing a later reoperation. However, some studies have reported that there is no correlation between smoking, radiological signs of degenerative cervical disease [24], and the radiological fusion rate after ACDF [25], but these studies have focused only on radiological signs.

Regarding the number of levels operated on, there was no statistically significant difference in terms of the number of further surgeries needed, although there was a slight trend toward more new surgeries being needed in patients with single-level ACDF, which is in concordance with research conducted by Hilibrand et al [4] and Lee et al. [6]. In contrast to previously published work, our study contained patients operated on with all of the most common ACDF techniques not involving plating; discectomy, bone autograft, and synthetic implants were performed in the same unit and by the same set of surgeons but at different periods of time, reflecting the evolution of the treatment strategy of choice in cervical surgery. Patients operated on with a synthetic cage for fusion had better clinical outcomes in the short-term follow-up, but there was no difference in long-term NDI scores. Patients who received only a discectomy seemed to require more further surgeries, but with the employment of propensity matching to adjust for inherent differences in the patient groups, this difference turned out to be insignificant. The slight trend of needing more further surgeries is likely only indicative of the longer available period of follow-up for discectomy patients. In the previous literature, there is no strong consensus about the optimal technique, and a simple discectomy has been reported to be both inferior [26] and equal [27] [28] to the use of implants in randomized controlled trials. Thus, more studies are needed to resolve this issue.

The median NDI score of patients was $12 \%$, with a mean of $18 \%$. Kato et al determined the mean NDI score in the general population to be $6.98 \%$ [17]. They also estimated the cut-off value to detect neck pain associated with disability to be $15 \%$. Burkhart et al [8] reported the mean NDI to be 14\% with a 17-45 year follow-up period, and Yang et al [29] 14.2\% with a >10 year follow-up period. Nunley et al [30] conducted a study with shorter follow-up of 12-24 months, and the median NDI was reported to be $18 \%$. Therefore, as with young adult patients, ACDF surgery seems to be associated with persistent mild neck disability symptoms in later life. However, $67 \%$ of patients were working at the time of responding to the questionnaire, $7 \%$ were unemployed, and $7 \%$ were on disability pension due to cervical problems. The employment rate of working age adults in Finland in August of 2017 was 70.5\%, and the unemployment rate was $7.5 \%$ [31]. Thus, the proportion of employed and unemployed patients resembles that of the general population. To our knowledge, there is no previous study estimating the long-term effects of surgically-treated 
degenerative cervical disorders on future working status, and thus more studies are needed to draw any further conclusions.

Regarding the results reported on the NDI in terms of satisfaction and employment status, the response rate was $59 \%$ of the original 476 patient cohort. The Finnish Institute for Health and Welfare has conducted many population-based health survey studies of the Finnish population. An overall response rate of $73.6 \%$ has been reported by this institute [32]. Thus, we find that the response rate in our study of $59 \%$ (63\% of those with available contact information) is good even if not optimal, since our survey concerns matters that were 12-28 years in the past for the patients. However, the survey response rate may vary between satisfied and unsatisfied patients as well as other subgroups, and this must be kept in mind in interpreting the results.

Total disc replacement (TDR) has been an increasingly common method of treating degenerative cervical disorders in recent years. Young patients with sufficient disc space and a highly mobile cervical spine are thought to represent the ideal population for TDR instead of ACDF. The data are conflicting, however, and both equal [29] and superior results to ACDF have been published [33] [34]. Nevertheless, because the method was first introduced in the early 2000s, data about long-term prognosis after TDR are still scarce. Dufour et al [35] reported 15 of 384 patients (4\%) to have undergone new cervical surgeries, excluding early revisions, in a five-year follow-up, with 10 cases relating to ASD and five to other cervical levels. In contrast, in a period of five years, 7.6\% (36/476) of patients in our study underwent another cervical surgery, with 6.3\% (30/476) of cases relating to ASD (early reoperations excluded). As we know, Yang et al [29] had the longest follow-up period thus far (>10 years), and they reported an almost equal occurrence rate of ASD (33-35\%) in the ACDF and TDR groups without the need for further cervical surgeries during the follow-up. Therefore, the long-term reoperation rates or occurrence of ASD do not seem to be superior with TDR to the longterm results presented here for ACDF among young adults.

\section{Conclusions}

In this study, the 10 -year reoperation rate was $12.3 \%$, with $10.3 \%$ attributed to ASD. The annual reoperation risk due to ASD, i.e. the annual incidence rate of ASD requiring surgery, was $1.1 \%$. The most important risk factors for needing a reoperation were clinical myelopathy before the index surgery and smoking at the time of the index surgery. Patients who were operated on with only a discectomy had similar NDI scores in the long-term follow-up and were not reoperated on more often, and it is likely that the slight trend in this direction merely reflects the longer available follow-up time. Therefore, discectomy alone still seems to be a vital alternative to the general modern practice of fusion with synthetic implants. The patient-reported long-term satisfaction levels with the surgery were very high, and the employment rate among patients resembled that of the general population in Finland. Thus, the long-term prognosis after ACDF performed at a younger age seems to be good even though ACDF surgery may be associated with persistent mild neck disability symptoms in later life. 


\section{References}

[1] K. Radhakrishnan, W. Litchy, W. O'Fallon and L. Kurland, "Epidemiology of cervical radiculopathy. A population-based study from Rochester, Minnesota, 1976 through 1990," Brain, vol. 117, no. 2, pp. 325-35, 1994.

[2] C. Lehmann, J. Buchovski, G. Stoker and K. Riew, "Neurologic Recovery after Anterior Cervical Discectomy and Fusion," Global Spine J, vol. 4, no. 1, pp. 41-6, 2014.

[3] J. Jagannathan, C. Shaffrey, R. Oskouian, A. Dumont, C. Herrold, C. Sansur and J. Jane, "Radiographic and clinical outcomes following single-level anterior cervical discectomy and allograft fusion without plate placement or cervical collar," J Neurosurg spine, vol. 8, no. 5, pp. 420-8, 2008.

[4] A. Hilibrand, G. Carlson, M. Palumbo, P. Jones and H. Bohlman, "Radiculopathy and Myelopathy at Segments Adjacent to the Site of a Previous Anterior Cervical Arthrodesis," J Bone Joint Surg Am, vol. 81, no. 4, pp. 419-28, 1999.

[5] J. Wu, L. Liu, H. Wen-Cheng, Y. Chen, C. Ko, C. Wu, T. Chen, H. Cheng and T. Su, "The incidence of adjacent segment disease requiring surgery after anterior cervical diskectomy and fusion: estimation using an 11-year comprehensive nationwide database in Taiwan," Neurosurgery, vol. 70, no. 3, pp. 594-601, 2012.

[6] J. Lee, S. Lee, C. Peters and K. Riew, "Adjacent Segment Pathology Requiring Reoperation After Anterior Cervical Arthrodesis: The influence of Smoking, Sex and Number of Operated Levels," Spine, vol. 40, no. 10, pp. E571-7, 2015.

[7] T. Saarinen, M. Niemelä, R. Kivisaari, J. Pitkäniemi, J. Pohjola and J. Hernesniemi, "Early and late reoperations after anterior cervical decompression and fusion during an 11-year follow-up," Acta Neurochir (Wien), vol. 155, no. 2, pp. 285-91, 2013.

[8] B. Burkhardt, M. Brielmaier, K. Scherdtfeger and J. Oertel, "Clinical outcome following anterior cervical discectomy and fusion with and without anterior cervical plating for the treatment of cervical disc herniation-a 25-year follow-up study," Neurosurg Rev, vol. 41, no. 2, pp. 473-82, 2018.

[9] J. Chung, S. Kim, S. Jung and K. Lee, "Clinical adjacent-segment pathology after anterior cervical discectomy and fusion: results after a minimum of 10-year follow-up," Spine J, vol. 14, no. 10, pp. 2290-8, 2014.

[10] W. Yue, W. Brodner and T. Highland, "Long-Term Results After Anterior Cervical Discectomy and Fusion With Allograft and Plating," Spine, vol. 30, no. 19, p. 2138-44, 2005.

[11] H. Ishihara, M. Kanamori, Y. Kawaguchi, H. Nakamura and T. Kimura, "Adjacent segment disease after anterior cervical interbody fusion," Spine J, vol. 4, no. 6, pp. 624-8, 2004. 
[12] G. Buttermann, "Anterior Cervical Discectomy and Fusion Outcomes over 10 years," Spine, vol. 43, no. 3, pp. 207-14, 2018.

[13] P. Rosenbaum and R. DB, "The Central Role of the Propensity Score in Observational Studies for Causal Effects," Biometrika, vol. 70, no. 1, pp. 41-55, 1983.

[14] H. Vernon and S. Mior, "The neck disability index: a study of reliability and validity," J Manip Physiol Ther, vol. 14, no. 7, pp. 409-15, 1991.

[15] A. Wheeler, P. Goolkasian, A. Baird and B. 2. Darden, "Development of the Neck Pain and Disability Scale. Item analysis, face, and criterion-related validity," Spine, vol. 24, no. 13, pp. 1290-4, 1999.

[16] P. Salo, J. Ylinen, H. Kautiainen, M. Arkela-Kautiainen and A. Häkkinen, "Reliability and validity of the finnish version of the neck disability index and the modified neck pain and disability scale," Spine, vol. 35, no. 5, pp. 552-6, 2010.

[17] S. Kato, K. Takeshita, K. Matsudaira, J. Tonosu, N. Hara and H. Chikuda, "Normative score and cut-off value of the Neck Disability Index," J Orthop Sci, vol. 17, no. 6, pp. 687-93, 2012.

[18] K. Fountas, E. Kapsalaki, L. Nikolakakos, H. Smisson, K. Johnston, A. Grigorian, G. Lee and J. J. Robinson, "Anterior cervical discectomy and fusion associated complications," Spine, vol. 32, no. 21, pp. 2310-7, 2007.

[19] M. Kelly, C. Eliasberg, R. Ajiboye, S. McAnany and N. SooHoo, "Reoperation and Complications after Anterior Cervical Discectomy and Fusion versus Cervical Disc Arthroplasty: A Study of 52,395 Cases," Eur Spine J, vol. 27, no. 6, pp. 1432-9, 2018.

[20] M. Shousha, M. Alhashash, H. Allouch and H. Boehm, "Reoperation rate after anterior cervical discectomy and fusion using standalone cages in degenerative disease: a study of 2,078 cases," Spine J, vol. 19, no. 12, pp. 2007-12, 2019.

[21] Finland National Institute for Health and Welfare, "Tobacco Statistics 2016," 2016.

[22] H. An, C. Silveri, J. Simpson, P. File, C. Simmons, F. Simeone and R. Balderston, "Comparison of smoking habits between patients with surgically confirmed herniated lumbar and cervical disc disease and controls," J Spinal Disord, vol. 7, no. 5, pp. 369-73, 1994.

[23] Z. Chen, X. Li, F. Pan, D. Wu and H. Li, "A retrospective study: Does cigarette smoking induce cervical disc degeneration?," Int J Surg, vol. 53, pp. 269-73, 2018.

[24] D. Gore, G. Carrera and S. Glaeser, "Smoking and degenerative changes of the cervical spine: a roentgenographic study," Spine J, vol. 6, no. 5, pp. 557-60, 2006.

[25] M. Luszczyk, J. Smith, J. Fischgrund, S. Ludwig, R. Sasso, C. Shaffrey and A. Vaccaro, "Does smoking have an impact on fusion rate in single-level anterior cervical discectomy and fusion with allograft and rigid plate fixation? Clinical article.," J Neurosurg Spine, vol. 19, no. 5, pp. 527-31, 2013. 
[26] C. Bärlocher, A. Barth, J. Krauss, R. Binggeli and R. Seiler, "Comparative evaluation of microdiscectomy only, autograft fusion, polymethylmethacrylate interposition, and threaded titanium cage fusion for treatment of single-level cervical disc disease: a prospective randomized study in 125 patients," Neurosurg Focus, vol. 12, no. 1, p. E4, 2002.

[27] R. Donk, A. Verbeek, W. Verhagen, H. Groenewoud, A. Hosman and R. Bartels, "What's the best surgical treatment for patients with cervical radiculopathy due to single-level degenerative disease? A randomized controlled trial," PLoS One, vol. 12, no. 8, p. e0183603, 2017.

[28] R. Nandoe Tewarie, R. Bartels and W. Peul, "Long-term outcome after anterior cervical discectomy without fusion," Eur Spine J, vol. 16, no. 9, p. 1411-6, 2007.

[29] S. Yang, Y. Zhu, S. Yan, J. Di, D. Yang and W. Ding, "Anterior cervical discectomy and fusion surgery versus total disc replacement: A comparative study with minimum of 10-year follow-up," Sci Rep, vol. 7, no. 1, p. 16443, 2017

[30] P. Nunley, A. Jawahar, E. Kerr, D. Cavanaugh, C. Howard and S. Brandao, "Choice of plate may affect outcomes for single versus multilevel ACDF: results of a prospective randomized single-blind trial," Spine J, vol. 9, no. 2, pp. 121-7, 2009.

[31] Statistics Finland, "Labour force survey," 8 2018. [Online]. Available: https://tilastokeskus.fi/til/tyti/2018/08/tyti_2018_08_2018-09-25_tie_001_en.html.

[32] A. Lundqvist and T. Mäki-Opas, "Health 2011 Survey - Methods," Finland National Institute for Health and Welfare, 2016.

[33] Y. Zhang, C. Liang, Y. Tao, X. Zhou, H. Li, F. Li and C. Q, "Cervical total disc replacement is superior to anterior cervical decompression and fusion: a meta-analysis of prospective randomized controlled trials," PLOS ONE, vol. 10, no. 3, p. e0117826, 2015.

[34] S. Xu, Y. Liang, Z. Zhu, Y. Qian and H. Liu, "Adjacent segment degeneration or disease after cervical total disc replacement: a meta-analysis of randomized controlled trials," J Orthop Surg Res, vol. 13, no. 1, p. 244, 2018.

[35] T. Dufour, J.-P. Steib, P. Bernard, J. Huppert, E. Lioret, P. Hieu, I. Hovorka and J. Beaurain, "Long-Term Safety and Reoperation Rates Following Cervical TDR: Prospective and Multicentric Study," Spine, vol. 16, no. 10, pp. S292-3, 2016.

\section{Figure captions}




\section{9 patients}

- All 18- to 39-year-old patients with ACDF done in the HUH Dept. of Neurosurgery between 1990 and 2005.

\section{6 patients included in the retrospective cohort study}

- All underwent thorough investigation of further medical records for identification of all re-referrals for surgical evaluation of cervical problems and further cervical surgeries;

- 430 patients (90\%) had a clinical follow-up at 2-3 months post-surgery; data collected as part of investigation of medical records.

- Three patients excluded because of previous cervical surgery;

- 10 patients excluded because of non-degenerative indications for surgery: two tumours, six fractures or other major traumas, one cervical inrenhilit., and ann -hromer

\section{3 patients (93\%) were sent additional questionnaires}

- NDI;

- General information and satisfaction with surgery.

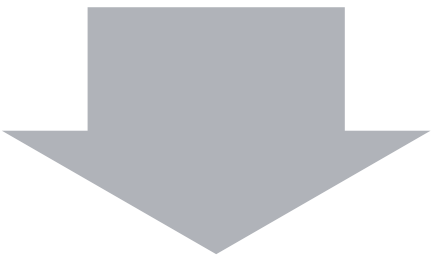

- Nine patients (5\%) died before commencement of this follow-up study;

- Five patients ( $2 \%$ ) with no available address in Finland.

\section{1 patients (59\%) answered the questionnaires}

- Including the parts of the study concerning questionnaire data (satisfaction with the surgery, employment status, and the NDI). 


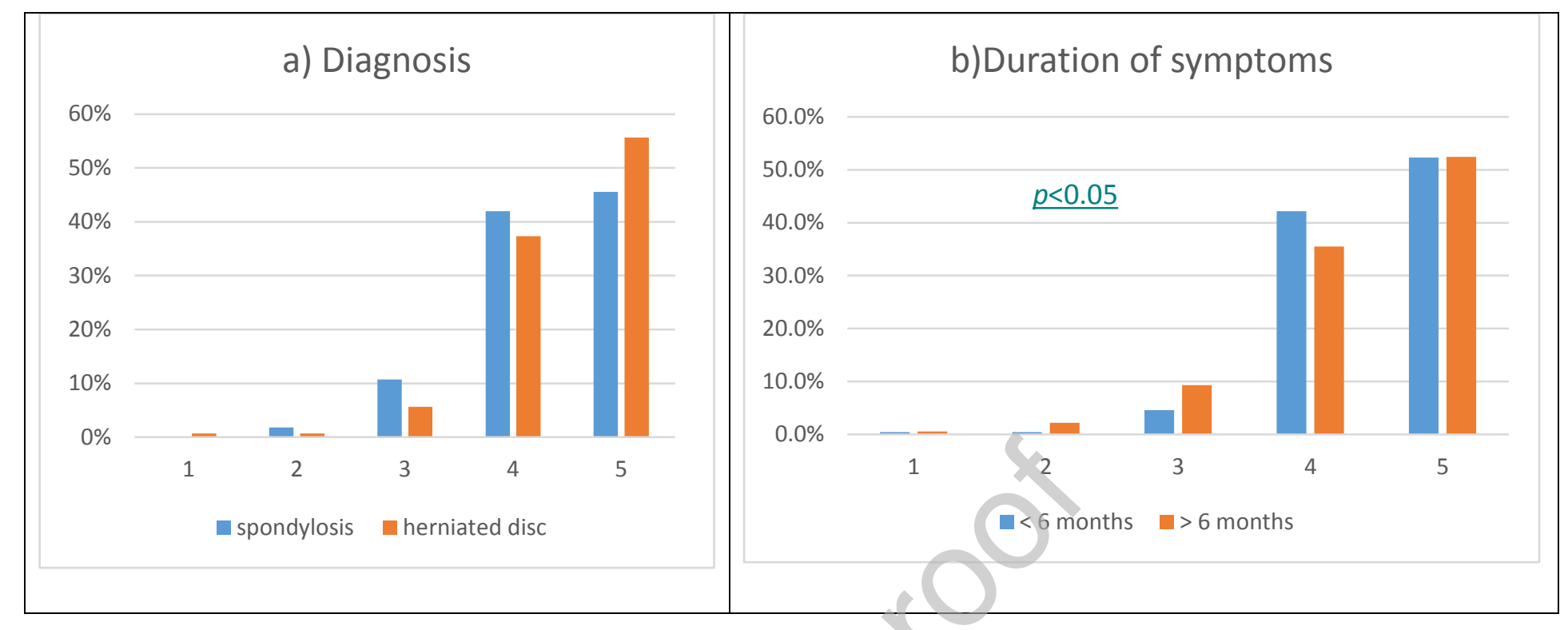

Figure 1: Number of patients represented as a flow chart. 


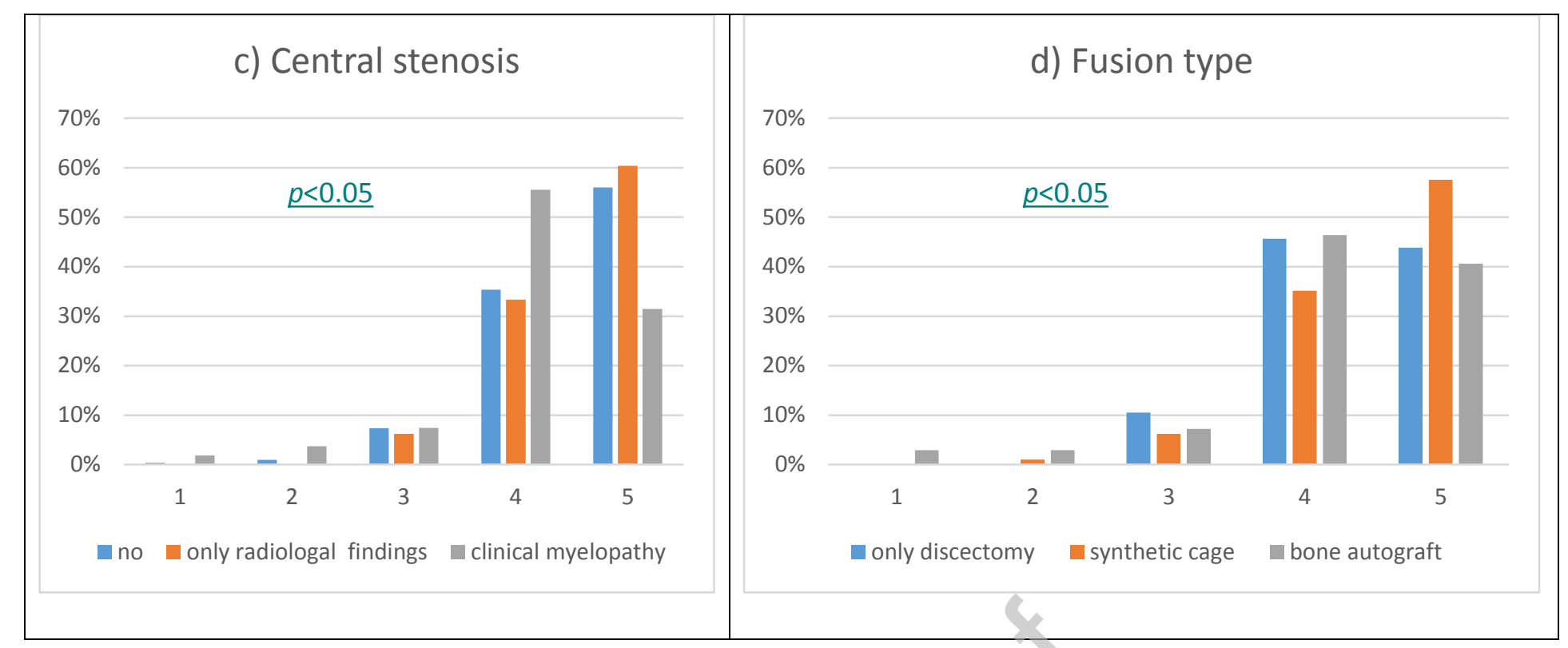

Figure 2 
Figure 2: The condition at the follow-up visit scored on Likert scale in terms of subgroups: (a) primary diagnosis (herniated intervertebral disc or spondylotic nerve root compression), (b) preoperative symptom duration, (c) the presence of radiological central stenosis or clinical myelopathy, and (d) fusion type with discectomy only, synthetic cage implant, or iliac bone autograft. Data and p-values are presented in more detail in Supplementary Table 1.

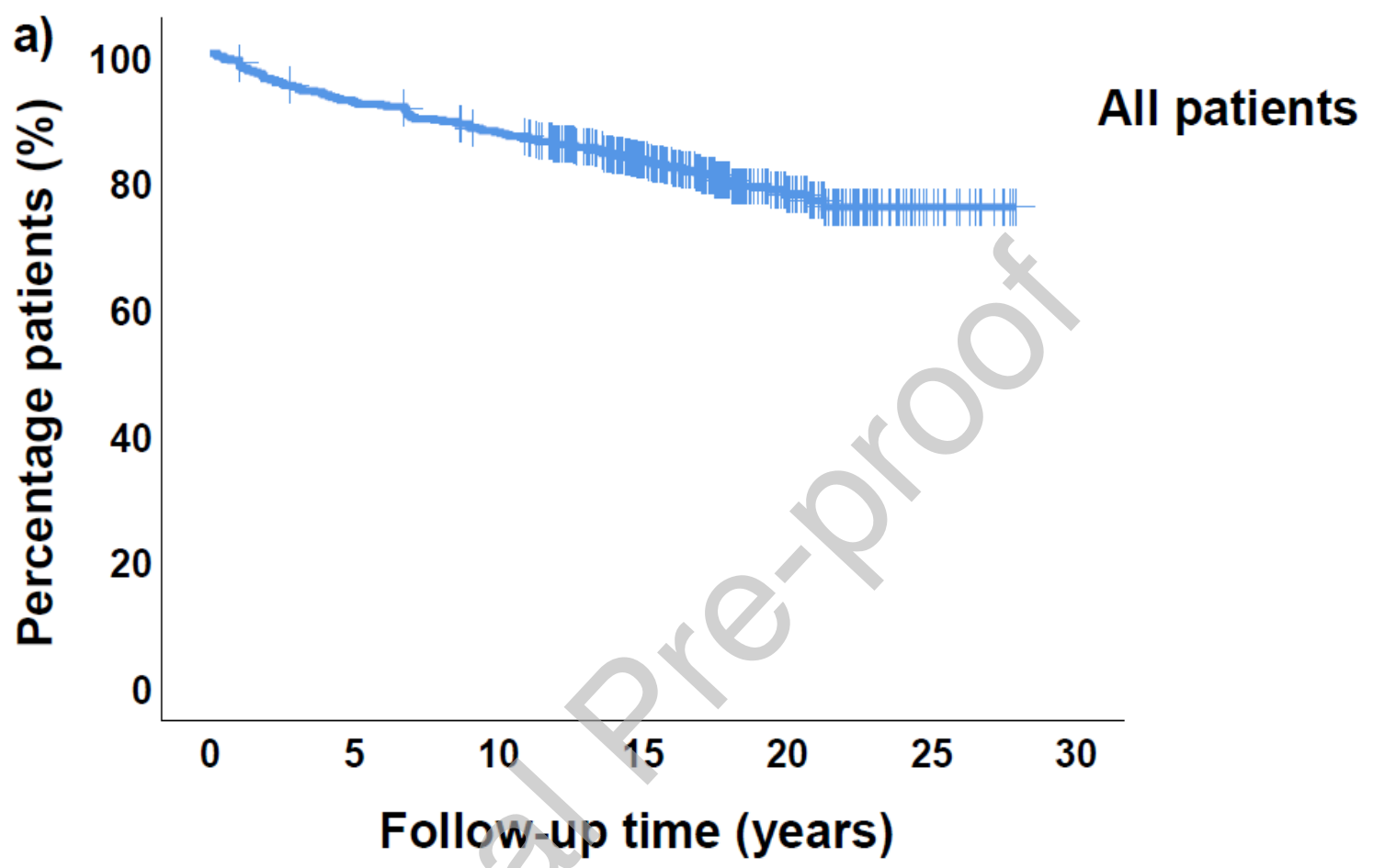



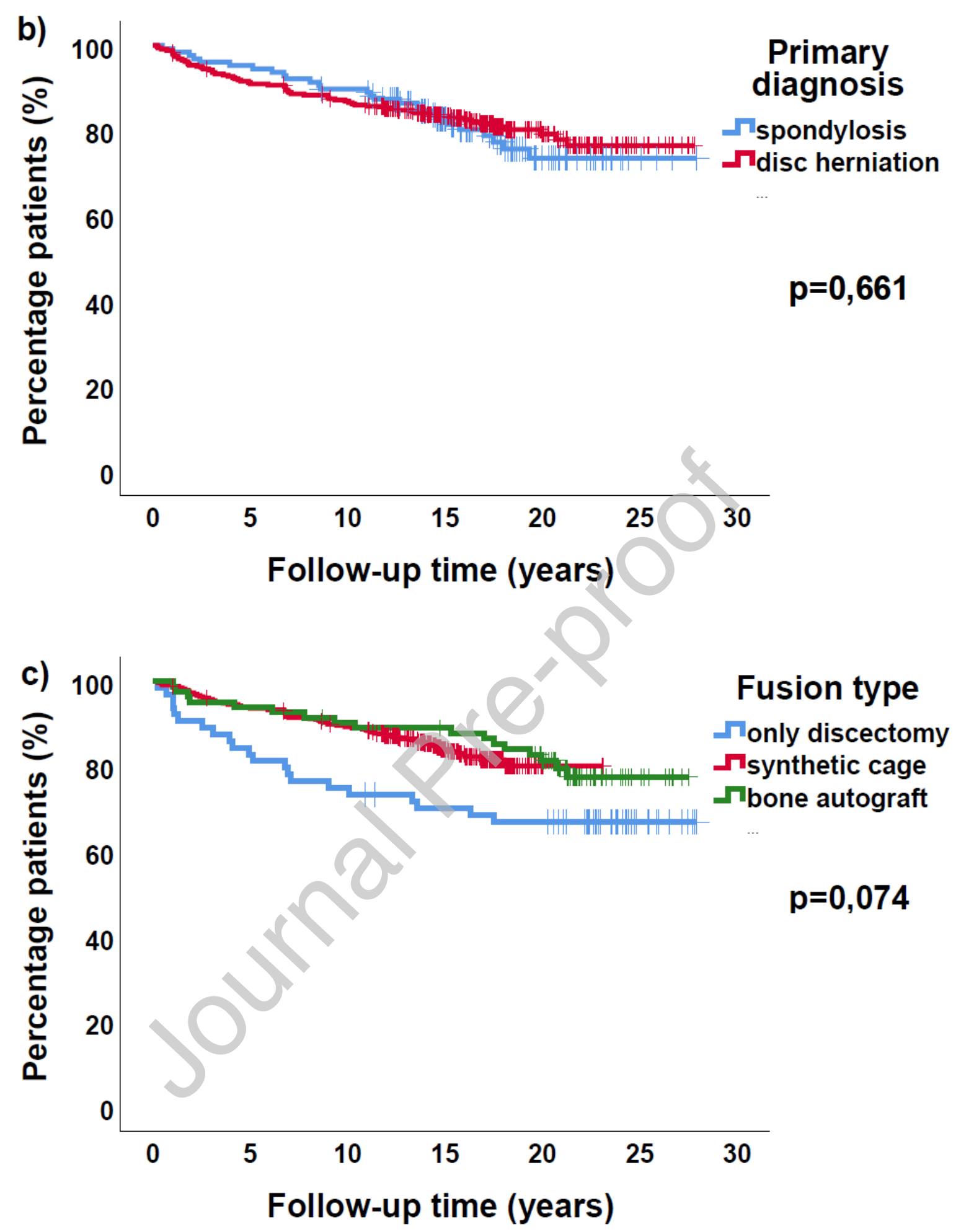

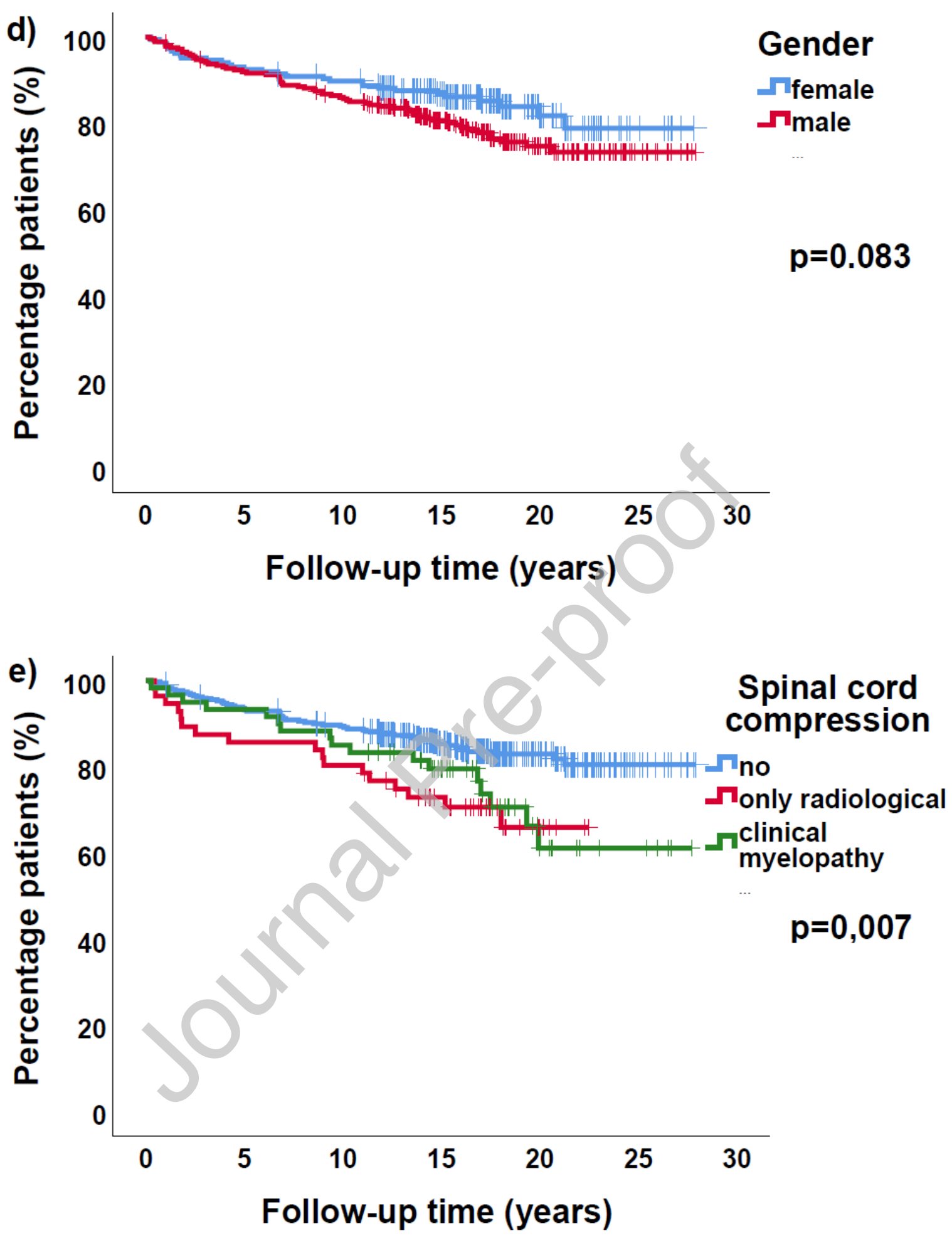


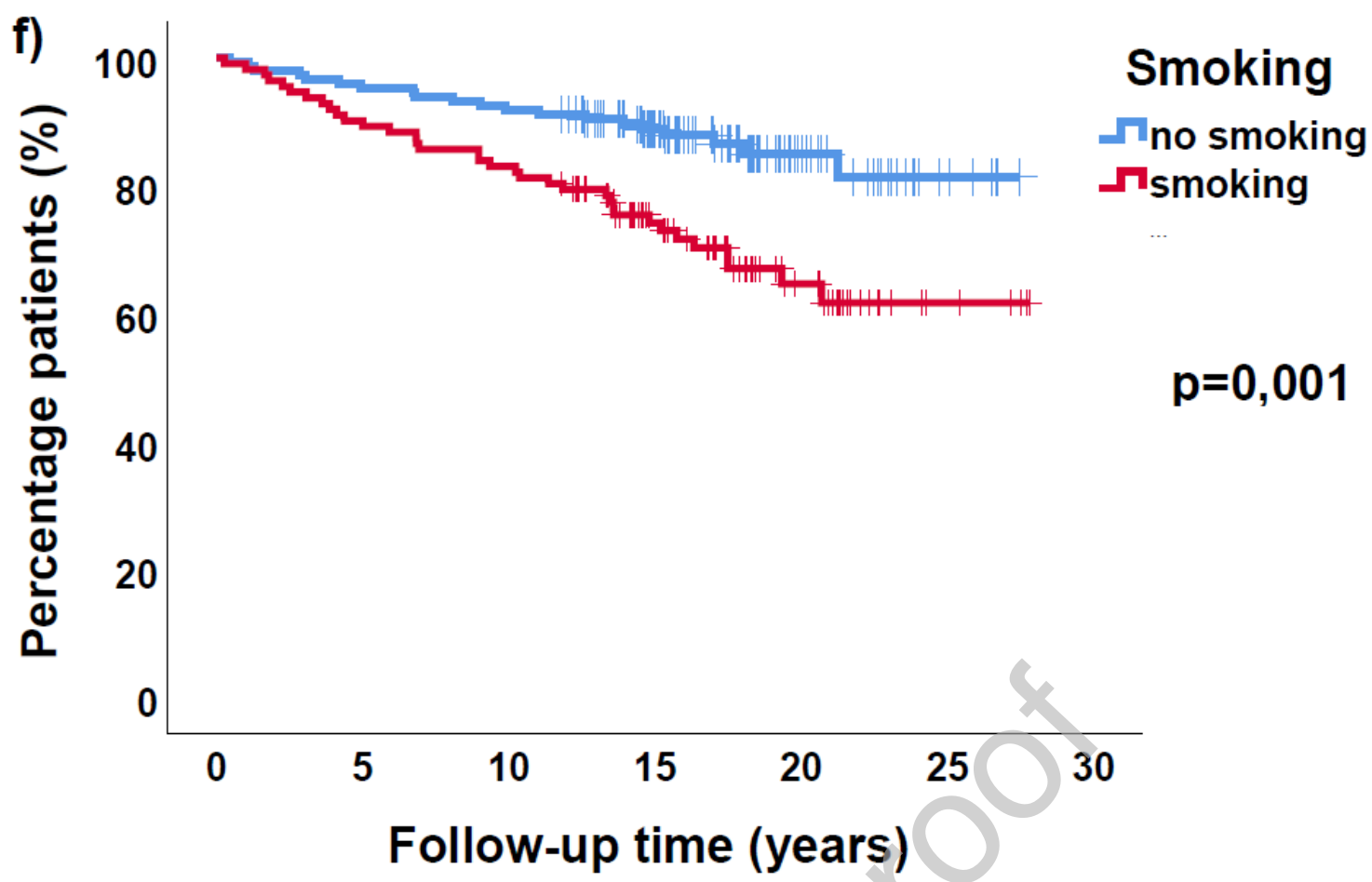

Figure 3: The percentage of patients who have not undergone a new cervical surgery presented as a Kaplan-Meier plot with the function of time in years. Early revision surgeries within 28 days are excluded (a) All patients, (b-f) Patients grouped by (b)primary diagnosis of spondylotic nerve root compression or disc herniation, (c) fusion type, (d) gender, (e) spinal cord compression, and (f) smoking status at the time of the primary surgery. Vertical lines represent the end of follow-up/sensoring. Statistically significant factors were central spinal cord compression and smoking status at the time of the operation. Patients with only a discectomy performed and men were operated on more often, but these differences were not statistically significant in the Kapplan-Meier analysis.

Table 1: Baseline information about patient population and surgeries

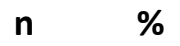

Total 
Under 30 
C4-C5

C5-C6

${ }^{1}$ radiological compression of spinal cord with

or without myelomalacia defined by

radiologist in standard radiological

assessment and reporting.

${ }^{2}$ clinical signs or symptoms of myelopathy 
Table 2: Rereferrals and reoperations (including revision surgeries after primary surgery and further cervical surgeries later in follow up).

$\begin{array}{lllllll}\text { Number of new referrals to the } & 0 & 1 & 2 & 3 & 4 & 5\end{array}$

\section{HUH neurosurgery}

$\begin{array}{lllllll}\text { all patients } & 321(67 \%) & 107(22 \%) & 31(7 \%) & 9(2 \%) & 6(1 \%) & 2(0 \%)\end{array}$

\begin{tabular}{llllllll}
\hline diagnosis & herniated & $247(72 \%)$ & $66(19 \%)$ & $20(6 \%)$ & $6(2 \%)$ & $4(1 \%)$ & $2(1 \%)$ \\
& disc \\
& & & & & & \\
\hline spondylosis & $73(57 \%)$ & $39(31 \%)$ & $10(8 \%)$ & $3(2 \%)$ & $2(2 \%)$ & $0(0 \%)$
\end{tabular}

\begin{tabular}{llllll}
\hline Number of reoperations & $\mathbf{0}$ & $\mathbf{1}$ & $\mathbf{2}$ & $\mathbf{3}$ & $\mathbf{4}$ \\
& & & & \\
\hline All patients & $364(76 \%)$ & $92(19 \%)$ & $14(3 \%)$ & $4(1 \%)$ & $2(0 \%)$ \\
& & & & \\
\hline
\end{tabular}

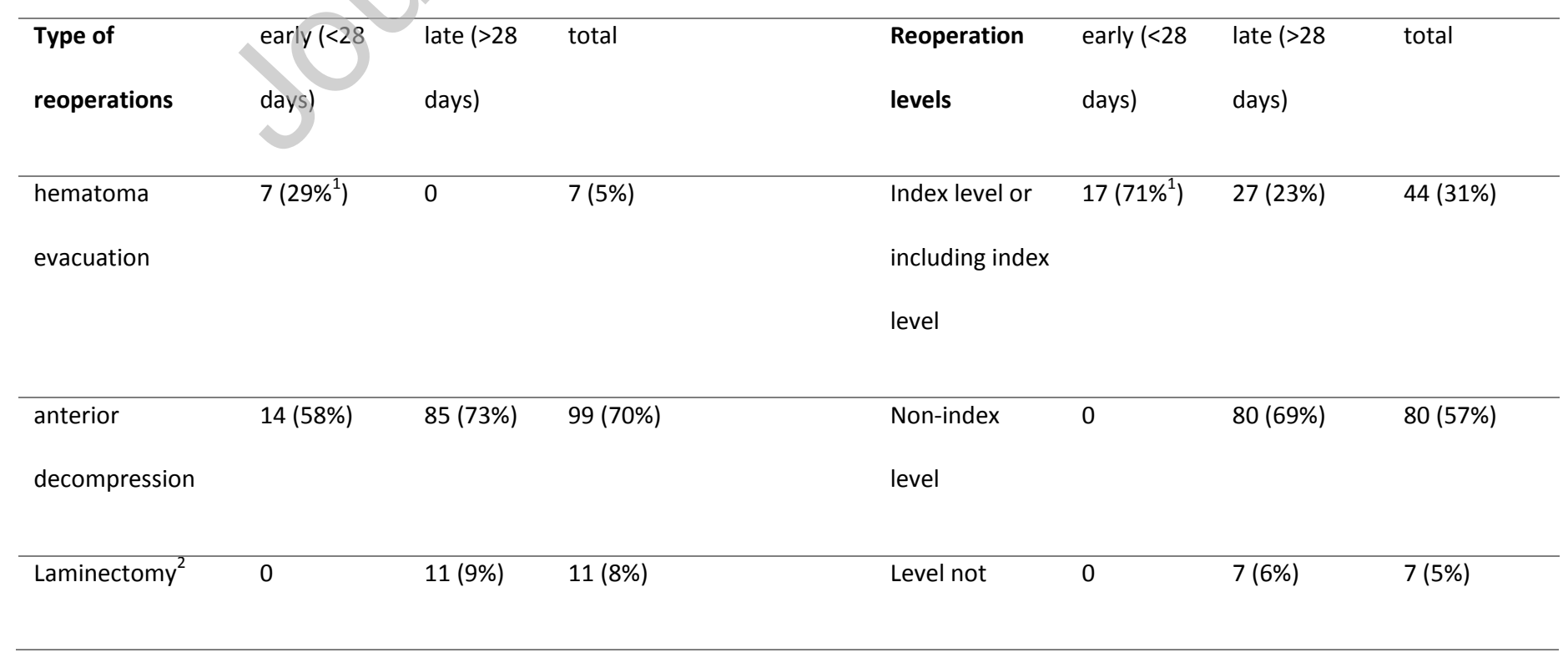


specified $^{3}$

\begin{tabular}{|c|c|c|c|c|c|c|c|}
\hline $\begin{array}{l}\text { posterior } \\
\text { foraminotomy }^{2}\end{array}$ & 0 & $8(7 \%)$ & $8(6 \%)$ & hematoma & 7 (29\%) & 0 & 7 (5\%) \\
\hline $\begin{array}{l}\text { bone autograft } \\
\text { removal }\end{array}$ & $2(8 \%)$ & 0 & $2(1 \%)$ & $\begin{array}{l}\text { epidural } \\
\text { stimulator }\end{array}$ & 0 & $2(2 \%)$ & $2(1 \%)$ \\
\hline $\begin{array}{l}\text { epidural } \\
\text { stimulator }\end{array}$ & 0 & $2(2 \%)$ & $2(1 \%)$ & all & $24(100 \%)$ & $116(100 \%)$ & $140(100 \%)$ \\
\hline $\begin{array}{l}\text { type not } \\
\text { specified }^{3}\end{array}$ & $1(4 \%)$ & $11(9 \%)$ & $12(9 \%)$ & & & & \\
\hline all & $24(100 \%)$ & $\begin{array}{l}117 \\
(100 \%)\end{array}$ & $\begin{array}{l}141 \\
(100 \%)\end{array}$ & & & & \\
\hline
\end{tabular}

${ }^{1}$ percentages from the total number of early and late reoperations

${ }^{2}$ One operation contained both laminectomy and posterior foraminotomy.

${ }^{3}$ operations done in other hospitals 
Table 3: Basic information questionnaires. 281 out of the original 476 patients (59\%) altogether returned the questionnaires.

Question (number of answers)

Employment status

(280)

unemployed

on disability pension

due to cervical problems

due to other reasons

reason not available

on part-time disability

$11(4 \%)$

pension

other (for example

$27(10 \%)$

studying, old age pension)
$19(7 \%)$

$36(13 \%)$

20

13

n (\%)

$187(67 \%)$

3

\begin{tabular}{lcc}
\hline Smoking (present) & yes & $70(25 \%)$ \\
& & \\
\hline$(275)$ & no & $205(75 \%)$
\end{tabular}

Smoking (at the time of the operation) yes $112(43 \%)$


Satisfaction to the result of the surgery

5 (very satisfied)

4 (satisfied)

3 (can't say)

2 (unsatisfied)

1 (very unsatisfied)
$3(1 \%)$

$182(65 \%)$

77 (27\%)

$13(5 \%)$

$6(2 \%)$

$259(96 \%)$

$11(4 \%)$

(270)

no 
Table 4: Summary of the results of NDI questionnaires send to the patientsnow at the end of follow up.

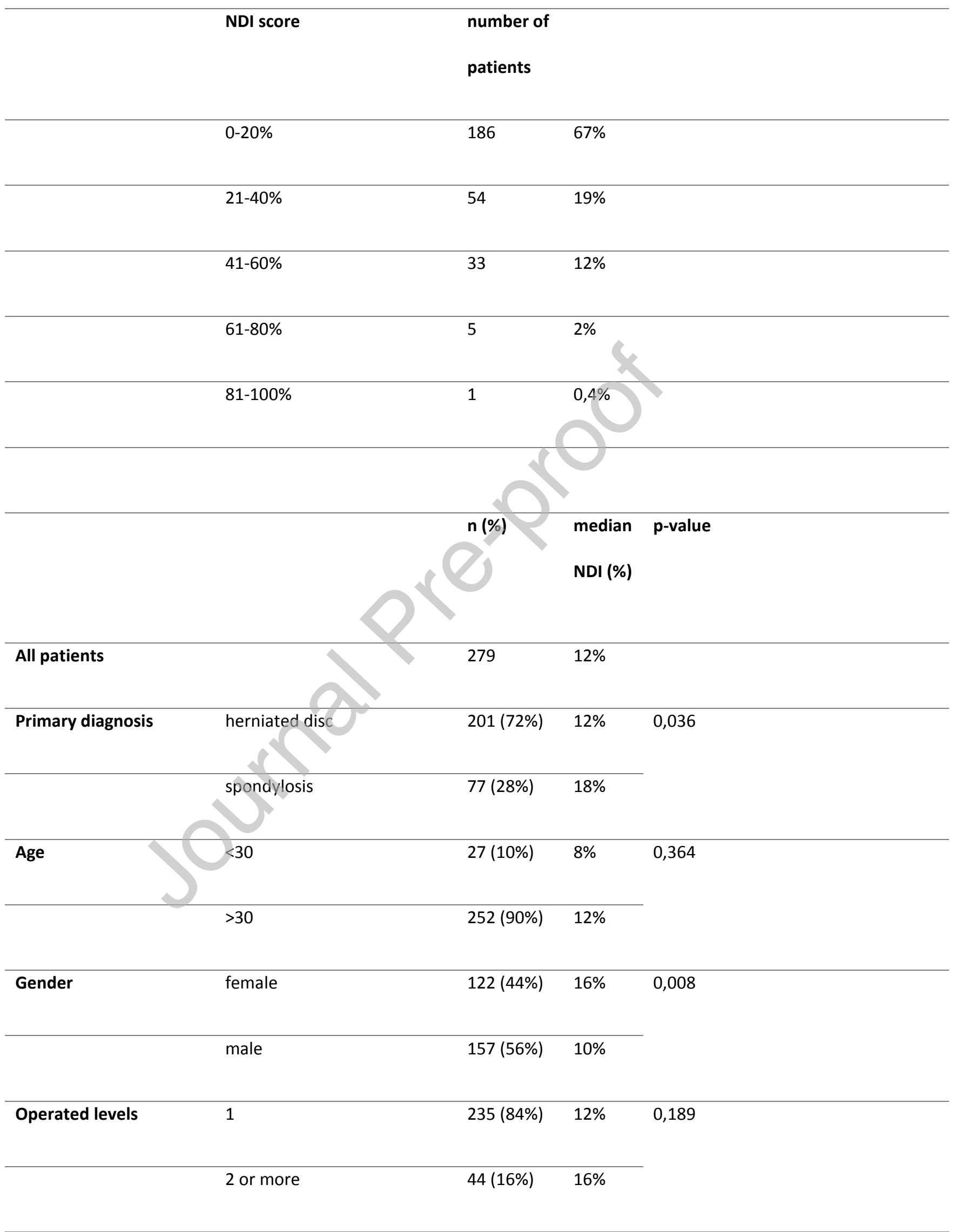




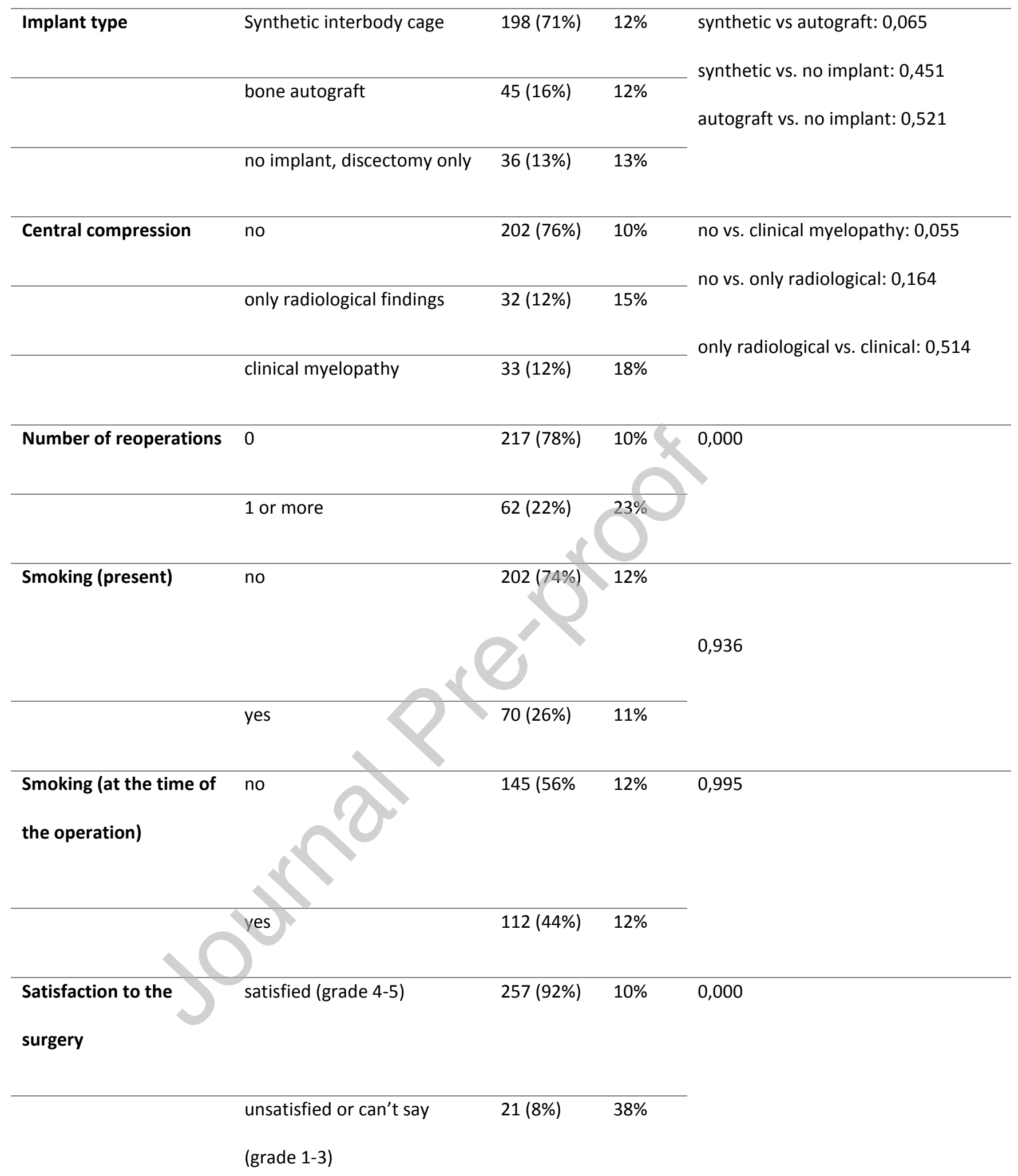

